\title{
CONHECIMENTO DOS EDUCADORES DO ABRIGO TEREZA DE JESUS SOBRE SAÚDE BUCAL INFANTIL
}

\section{KNOWLEDGE OF CHILD ORAL HEALTH AMONG TEREZA DE JESUS SHELTER EDUCATORS}

\author{
Júnia Rédua Bispo* \\ Andrea Graciene Lopez Ramos Valente** \\ Lúcia Helena Raymundo de Andrade ${ }^{* *}$ \\ Patricia Nivoloni Tannure***
}

\begin{abstract}
RESUMO
Introdução. A escola é um espaço social propício para a execução de programas de saúde bucal, pois nela as crianças estão reunidas e receptivas para participar de ações educativas e preventivas. Diante desse quadro, o educador deve aproveitar a oportunidade para exercer uma influência positiva sobre as crianças e motivá-las, a fim de desenvolverem bons hábitos de higiene bucal. Objetivo: O objetivo deste trabalho foi avaliar o nível de conhecimento dos educadores do Abrigo Tereza de Jesus, RJ, sobre saúde bucal infantil. Métodos: Foram entrevistados 55 educadores. Dados a respeito da idade, sexo, grau de instrução e tempo de trabalho foram coletados. Foi utilizado, ainda, um questionário previamente publicado com informações sobre saúde bucal, etiologia da doença cárie, placa bacteriana, doença periodontal, flúor e escovação. Resultados: Os educadores apresentaram um razoável conhecimento sobre a etiologia da cárie e doença periodontal. Em contrapartida, relataram um satisfatório conhecimento sobre odontologia preventiva. Os fatores idade do educador e tempo de trabalho não mostraram associação com o grau de conhecimento sobre saúde bucal. Conclusão: Há, portanto, a necessidade da introdução de um projeto visando transferir informações sobre saúde bucal à população estudada e estreitar a ligação entre os educadores e cirurgiões-dentistas.
\end{abstract}

Descritores: Serviços de saúde da criança • Saúde bucal • Promoção da saúde • Odontopediatria • Assistência odontológica para crianças.

\begin{abstract}
Introduction. The school is a social space conducive to the implementation of oral health programs because its children are organized by appropriate ages to participate in educational and preventive actions. Given this situation, the educator should take the opportunity to exert a positive influence on children and motivate them to develop healthy oral hygiene habits. Objective: The objective of this study was to evaluate the level of knowledge of Tereza of Jesus Shelter educators, RJ, on child oral health. Methods: We interviewed 55 educators. Data regarding age, gender, education level and working time were collected. It was also used a questionnaire previously published containing information on oral health, etiology of dental caries, plaque, periodontal disease, fluoride and brushing. Results: The educators had a reasonable knowledge of the etiology of caries and periodontal disease. In contrast, they had a satisfactory knowledge of preventive dentistry. The factors age of educator and his working time were not associated with the degree of knowledge about oral health. Conclusion: Regarding this fact, there is a need to introduce a project to transfer information on oral health in the population studied and to strengthen the link between educators and dentists.
\end{abstract}

Descriptors: Child health services; Oral health; Health promotion; Pediatric dentistry; Dental care for children.

* Graduanda em Odontologia - Universidade Veiga de Almeida (UVA)

** Mestre em Odontologia (Odontopediatria), Professora da Disciplina de Odontopediatria - Universidade Veiga de Almeida (UVA) 


\section{INTRODUÇÃO}

A Odontologia está em constante transformação. Sabe-se que grandes avanços no que diz respeito aos conhecimentos técnico-científicos e à prevenção têm sido alcançados, entretanto, as doenças bucais continuam atingindo grande parcela da população ${ }^{1}$. Apesar de os benefícios da mudança de hábitos de vida serem bem conhecidos pelos profissionais da saúde, nem sempre são de conhecimento da população em geral².

A escola é um espaço social propício para a execução de programas de saúde bucal $^{3}$, uma vez que as crianças podem participar de ações educativas e preventivas. Além disso, é um cenário onde todos podem agir com o objetivo comum de promover os cuidados com a saúde bucal, já que esses cuidados são de responsabilidade não só do cirurgião-dentista, mas também dos educadores, dos cuidadores das crianças e dos pais ${ }^{4}$.

Os pré-escolares passam grande parte do dia na escola e são receptivos e dispostos a aprender. Diante desse quadro, o educador deve aproveitar a oportunidade para exercer uma influência positiva sobre as crianças e motivar-lhes o desenvolvimento de hábitos de higiene bucal. Assim, ele tem importância primordial no bom êxito da parceria entre a educação e odontologia e, consequentemente, na prevenção de doenças bucais, como a cárie dentária e a doença periodontal ${ }^{3}$.

A doença cárie pode influenciar no desenvolvimento da criança e na sua participação em atividades importantes da vida. A presença de dor, infecção ou disfunção no sistema estomatognático podem restringir o consumo de uma dieta adequada às necessidades energéticas, afetando o crescimento da criança, bem como o aprendizado, a comunicação e a recreação ${ }^{5}$. Dentro desse contexto, o objetivo deste estudo foi avaliar o nível de conhecimento dos educadores do Abrigo Tereza de Jesus, RJ, sobre saúde bucal infantil.

\section{MATERIAIS E MÉTODOS}

Este estudo faz parte de um Projeto de Pesquisa e Extensão do Curso de Odontologia da Universidade Veiga de Almeida, denominado "AVALIAÇÃO DA CONDIÇÃO DE SAÚDE BUCAL DE CRIANÇAS DE UM ABRIGO DA CIDADE DO RIO DE JANEIRO PARA IMPLANTAÇÃO DE UM PROGRAMA DE PROMOÇÃ̃ DE SAÚDE BUCAL" sob responsabilidade da Professora Patricia Nivoloni Tannure.

O projeto de pesquisa deste estudo foi submetido à aprovação do Comitê de Ética em Pesquisa da Universidade Veiga de Almeida ( $\mathrm{n}^{\circ}$ do parecer: 1.010.748), sendo que todos os participantes assinaram o Termo de Consentimento Livre e Esclarecido.

O instrumento de análise utilizado foi um questionário sobre saúde bucal previamente publicado ${ }^{6}$, anônimo e autoaplicável, o qual permitiu a obtenção de respostas objetivas. Ele continha uma pergunta sobre a fonte de informação e questões específicas sobre etiologia da doença cárie, placa bacteriana, doença periodontal, flúor e escovação. O questionário foi respondido durante o segundo semestre do ano de 2015.

Participaram do estudo todas as funcionárias do Abrigo que estavam no exercício da profissão no momento da pesquisa. As educadoras estavam envolvidas na educação das crianças de forma direta, dentre elas, professoras e auxiliares, em sua maioria.

Para avaliar o nível de informações dos participantes da pesquisa, foi considerada a frequência de 0 a $50 \%$ de acerto das questões propostas como conhecimento insatisfatório; 50 a $70 \%$ como conhecimento razoável e acima de $70 \%$ como conhecimento satisfatório. ${ }^{6}$

Os dados coletados foram inseridos no Programa SPSS (Statistical Package for Social Science) 21.0 IBM $®$ e analisados descritivamente. Nas análises comparativas entre a idade e o gênero dos participantes e as variáveis avaliadas utilizou-se o teste Qui-quadrado e exato de Fischer com nível de significância de 5\%.

\section{RESULTADOS}

O estudo foi realizado com 55 educadores do Abrigo Tereza de Jesus de um total de 65 profissionais. A média de idade dos educadores foi de $36( \pm 12,9)$ anos. Somente um educador era do sexo mas-
BISPO JR

VALENTE AGLR

ANDRADE LHR

TANNURE PN

CONHECIMENTO

DOS EDUCADORES

DO ABRIGO

TEREZA DE

JESUS SOBRE

SAÚDE BUCAL

INFANTIL

$\therefore 203$

REV, ODONTOL.

UnIV. CID. São

PAULO

2015; 27(3): 202-

9 , SET-DEZ 
BISPO JR

VALENTE AGLR

ANDRADE LHR

TANNURE PN

CONHECIMENTO

DOS EDUCADORES

DO ABRIGO

TEREZA DE

JESUS SOBRE

SAUUDE BUCAL

INFANTIL

Gráfico 1. Distribuição dos educadores $(n=55)$ do Abrigo Tereza de Jesus (RJ) segundo o grau de escolaridade (\%).

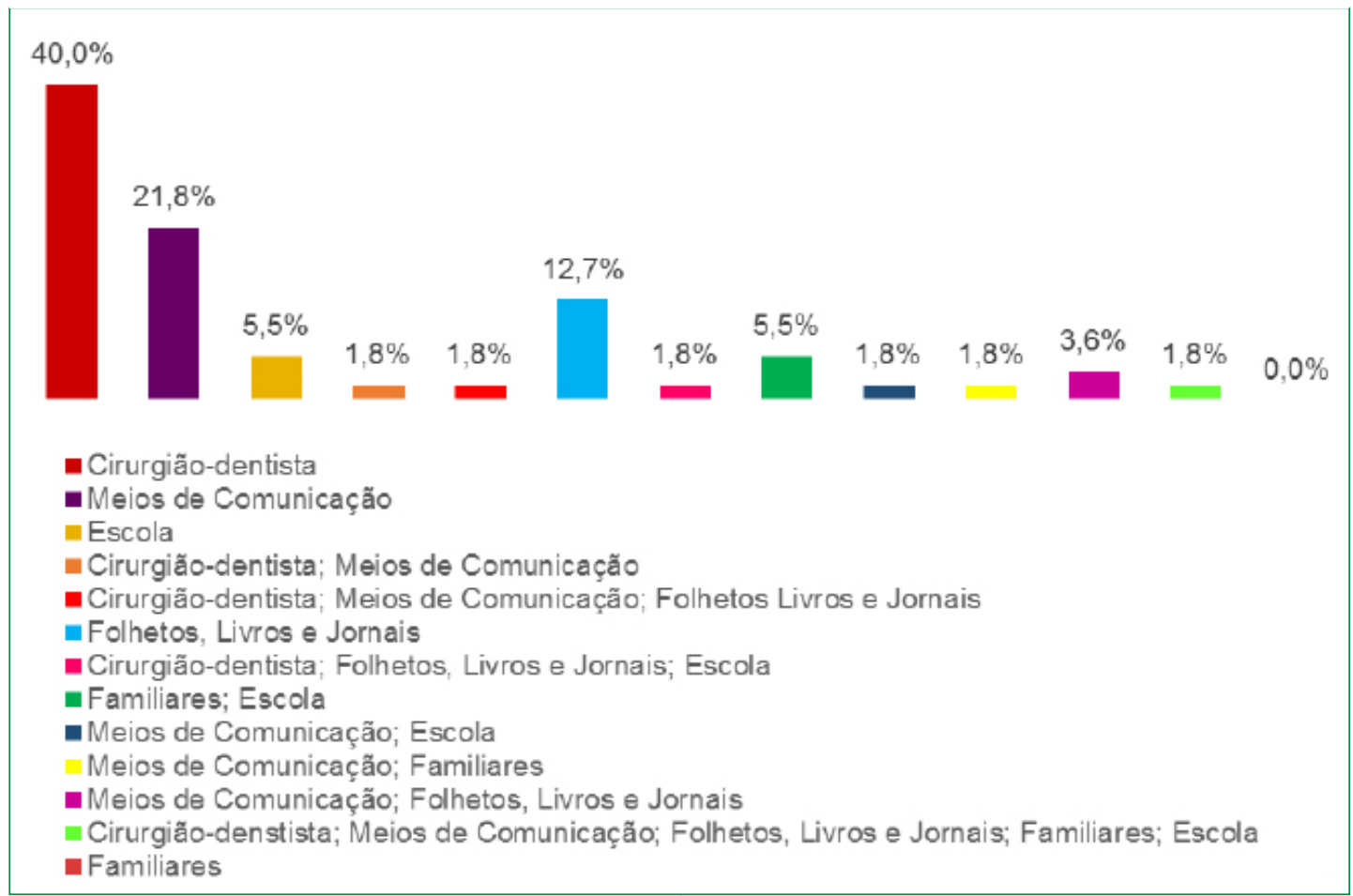

culino.

O Gráfico 1 exibe o nível de escolaridade dos educadores. Pode-se observar que a maioria dos profissionais $(58,2 \%)$ possui ensino médio completo.

Todos os pesquisados afirmaram ter algum conhecimento sobre saúde bucal. No Gráfico 2 é possível observar que o cirurgião-dentista $(40 \%)$ foi a fonte de informação mais citada entre os educadores sobre a prevenção de doenças bucais. Observou-se a baixa participação da escola como fonte de conhecimento sobre odontologia preventiva. Somente 3 profissionais $(5,5 \%)$ citaram a instituição de ensino como sendo o principal meio de obtenção de informações sobre saúde bucal. Entretanto, 6 profissionais (10,9\%) associaram a instituição de ensino como meio de obtenção de informações a outras opções apresentadas.

Na Tabela 1 pode ser observado o conhecimento dos participantes sobre a etiologia da cárie e da doença periodontal. A placa bacteriana foi definida por $38,2 \%$ como uma "massa amarelada sobre a superfície dental". A grande maioria (80\%) afirmou que sua remoção deve ser feita

Gráfico 2. Distribuição das fontes de informação recebidas pelos educadores ( $n=55)$ sobre prevenção em odontologia.
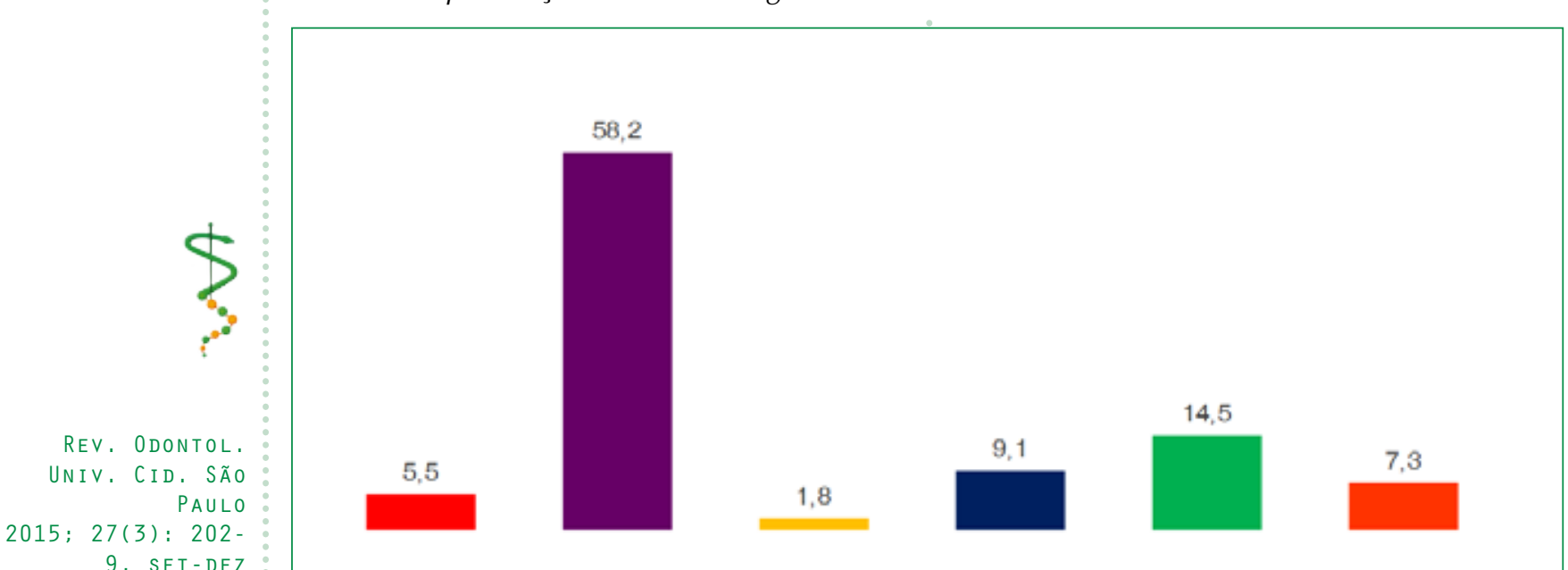


\begin{tabular}{|c|c|c|c|}
\hline \multirow{2}{*}{ Variável } & \multirow{2}{*}{ Respostas } & \multicolumn{2}{|c|}{ Frequência } \\
\hline & & $\mathrm{n}$ & $\%$ \\
\hline \multirow{4}{*}{$\begin{array}{l}\text { Que alimentos estão dire- } \\
\text { tamente relacionados ao } \\
\text { aparecimento da cárie? }\end{array}$} & Açúcares & 47 & 85,5 \\
\hline & Açúcares; Massas & 1 & 1,8 \\
\hline & As três alternativas & 7 & 12,7 \\
\hline & TOTAL & 55 & 100,0 \\
\hline \multirow[t]{7}{*}{ O que é placa bacteriana? } & Restos de alimentos & 13 & 23,6 \\
\hline & Restos de alimentos; Massa amarelada & 1 & 1,8 \\
\hline & Grupos de bactérias & 16 & 29,1 \\
\hline & Grupos de bactérias; Massa amarelada & 1 & 1,8 \\
\hline & Massa amarelada & 21 & 38,2 \\
\hline & Não sei & 3 & 5,5 \\
\hline & TOTAL & 55 & 100,0 \\
\hline \multirow{6}{*}{$\begin{array}{l}\text { De que maneira pode ser re- } \\
\text { movida a placa bacteriana? }\end{array}$} & Raspagem profissional & 44 & 80,0 \\
\hline & Raspagem profissional; Bochechos & 1 & 1,8 \\
\hline & Raspagem profissional; Fio e escova dental & 1 & 1,8 \\
\hline & Fio e escova dental & 7 & 12,7 \\
\hline & Fio e escova dental; Bochechos & 2 & 3,6 \\
\hline & TOTAL & 55 & 100,0 \\
\hline \multirow[t]{7}{*}{ A gengivite surge quando? } & Acúmulo de placa bacteriana & 31 & 56,4 \\
\hline & Acúmulo de placa bacteriana; Tendência & 2 & 3,6 \\
\hline & & 11 & 20,0 \\
\hline & Tendência para adquirir a doença & 4 & 7,3 \\
\hline & Sem motivo aparente & 7 & 12,7 \\
\hline & Não sei & 55 & 100,0 \\
\hline & TOTAL & & \\
\hline \multirow{7}{*}{$\begin{array}{l}\text { A cárie dentária surge quan- } \\
\text { do? }\end{array}$} & Escovação não adequada & 22 & 40,0 \\
\hline & Açúcar em excesso & 12 & 21,8 \\
\hline & As três alternativas & 14 & 25,5 \\
\hline & Açúcar em excesso; Escovação não adequa- & 6 & 10,9 \\
\hline & & 1 & 1,8 \\
\hline & Não sei & 55 & 100,0 \\
\hline & TOTAL & & \\
\hline \multirow{4}{*}{$\begin{array}{l}\text { A cárie é transmissível de } \\
\text { uma pessoa para outra? }\end{array}$} & Sim & 11 & 20,0 \\
\hline & Não & 36 & 65,5 \\
\hline & Não sei & 8 & 14,5 \\
\hline & TOTAL & 55 & 100,0 \\
\hline
\end{tabular}

Tabela 1. Conhecimento dos educadores $(n=55)$ sobre cárie e doença periodontal.

ISPO JR

VALENTE AGLR

ANDRADE LHR

TANNURE PN

CONHECIMENTO

DOS EDUCADORES

DO ABRIGO

teREzA DE

JESUS SOBRE

SAÚdE BUCAL

INFANTIL 
BISPO JR

VALENTE AGLR

ANDRADE LHR

TANNURE PN :

CONHECIMENTO

DOS EDUCADORES

DO ABRIGO

TEREZA DE

JESUS SOBRE

SAUUDE BUCAL

INFANTIL

\section{6}

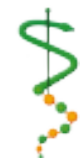

REV. ODONTOL.

UNIV. CID. SÃO

PAULO

2015; 27(3): 202-

9, SET-DEZ através de raspagem profissional. A cárie foi considerada uma doença não transmissível por $65,5 \%$ dos participantes.

Na Tabela 2 observou-se que 50,9\% dos participantes acreditavam que a quantidade de creme dental para escovação é uma porção equivalente a um grão de ervilha. Sobre a função do flúor, $87,3 \%$ indicaram que é fortalecer os dentes contra a cárie e em relação ao que é mais importante na escovação, 92,7\% indicaram ser a técnica utilizada.

Não houve associação positiva entre idade e tempo de trabalho em relação à etiología da cárie, doença periodontal e odontologia preventiva ( $p>0,05)$.

\section{DISCUSSÃO}

De maneira positiva, nesta pesquisa pôde-se notar que todos os funcionários relataram possuir algum tipo de conhecimento sobre saúde bucal. Observou-se que os profissionais da Odontologia ocuparam um local de destaque como fonte de informação (40\%). Esse resultado também foi descrito por Santos et al. ${ }^{1}$ e Antunes et al. $^{7}$ ao relatarem que a maioria dos professores também haviam recebido informações de cirurgiões-dentistas.

A literatura descreve uma baixa participação da escola como fonte de conhecimento sobre odontologia preventiva ${ }^{1}$, resultado semelhante foi observado neste estudo. Considerando-se essencial para o sucesso de programas educativos e preventivos em Odontologia uma maior participação dos professores, observou-se, em estudos prévios, que durante a formação do educador não existiu uma preocupação, por parte da instituição de ensino, em informá-los sobre saúde bucal ${ }^{6,7}$.

Quanto à dieta cariogênica, 85,5\% dos participantes indicaram, de forma correta, o açúcar como o principal alimento relacionado à lesão cariosa, assim como $40 \%$ associaram o surgimento da cárie à escovação não adequada. Em pesquisa realizada por Garcia et al. ${ }^{8}(2002)$, de maneira contrária ao presente estudo, apenas 9\%dos professores de escola pública responderam corretamente sobre a necessidade de uma dieta rica em açúcar associada à má higiene para o aparecimento da cárie. Semelhante ao estudo aqui presen- te, Wyne et al. ${ }^{9}$ relataram que a maioria dos professores entrevistados atribuíram o desenvolvimento da cárie dental à ingestão frequente de açúcares e à higiene bucal inadequada.

Grande parte dos educadores não acreditaram no caráter de transmissibilidade da cárie. Vale ressaltar que a cárie não é considerada uma doença transmissível e tem sido considerada uma disbiose. A sua causa pode ser explicada pela existência de diferentes espécies de microrganismos (polimicrobiana) que estão presentes também em condição de saúde (comensalismo). Entretanto, os microrganismos apresentam potencial patogênico em condição de desequilíbrio e o tratamento a ser feito é restabelecer o equilíbrio da flora bucal ${ }^{10}$. Com isso, conclui-se que os hábitos de higiene e dieta é que podem ser transmitidos de uma pessoa para outra. Entretanto, pode-se ainda encontrar na literatura autores que afirmam que a cárie é uma doença transmissível ${ }^{2,6,11}$.

A respeito do significado da placa bacteriana ou biofilme dental apenas 29,1\% dos participantes responderam, de forma correta, como sendo um "grupo de bactérias sobre a superfície dental". E a maioria $(38,2 \%)$ afirmou ser uma "massa amarelada sobre a superfície dental". Essa visão simplista sobre placa pode ser culpa do próprio dentista, devido à linguagem popular que utiliza, ao definir placa como "sujeirinha"11. Resultados semelhantes foram encontrados nos estudos de Garbin et al. ${ }^{11}$ (2013) e Aragão et al. ${ }^{6}$ (2010)

O estabelecimento da gengivite foi compreendido pela maioria dos participantes como o acúmulo de placa bacteriana. A pesquisa realizada por Antunes et al. ${ }^{6}$ (2007) corrobora com esse resultado, uma vez que $40,9 \%$ dos participantes indicaram a placa bacteriana como a principal causa para doenças da gengiva.

A quantidade de dentifrício e a presença de flúor em sua composição devem ser observadas com muita atenção, principalmente na primeira infância ${ }^{2,12,13}$. Quando questionados sobre a quantidade de creme dental utilizada na escovação, 50,9\% responderam de forma correta que deveria ser uma "porção equivalente a um grão de ervilha" e 41,8\% indicaram ser uma 


\begin{tabular}{|c|c|c|c|}
\hline \multirow[t]{2}{*}{ Variável } & \multirow[t]{2}{*}{ Respostas } & \multicolumn{2}{|c|}{ Frequências } \\
\hline & & $\mathbf{n}$ & $\%$ \\
\hline \multirow{5}{*}{$\begin{array}{l}\text { Qual a quantidade de cre- } \\
\text { me dental para escovação? }\end{array}$} & Equivalente a um grão de ervilha & 28 & 50,9 \\
\hline & Quantidade que cubra toda a escova & 23 & 41,8 \\
\hline & Produza espuma em abundância & 2 & 3,6 \\
\hline & Não sei & 2 & 3,6 \\
\hline & TOTAL & 55 & 100,0 \\
\hline \multirow[t]{6}{*}{ Qual a função do flúor? } & Clareamento dental & 3 & 5,5 \\
\hline & Fortalecer os dentes & 48 & 87,3 \\
\hline & Fortalecer os dentes; Hálito agradável & 1 & 1,8 \\
\hline & Hálito agradável & 2 & 3,6 \\
\hline & Não sei & 1 & 1,8 \\
\hline & TOTAL & 55 & 100,0 \\
\hline \multirow{6}{*}{$\begin{array}{l}\text { Como deve ser a esco- } \\
\text { va dental utilizada pela } \\
\text { criança? }\end{array}$} & Grande com cerdas macias & 7 & 12,7 \\
\hline & Pequena com cerdas macias & 45 & 81,8 \\
\hline & Pequena com cerdas duras & 2 & 3,6 \\
\hline & Pequena com cerdas macias; Grande com & 1 & 1,8 \\
\hline & cel & 55 & 100,0 \\
\hline & TOTAL & & \\
\hline \multirow{5}{*}{$\begin{array}{l}\text { O que é mais importante } \\
\text { na escovação dental? }\end{array}$} & Força aplicada & 1 & 1,8 \\
\hline & Técnica Utilizada & 52 & 94,5 \\
\hline & Técnica Utilizada; Quantidade de creme dental & 1 & 1,8 \\
\hline & Não sei & 1 & 1,8 \\
\hline & TOTAL & 55 & 100,0 \\
\hline
\end{tabular}

Tabela 2. Conhecimento dos educadores $(n=55)$ sobre odontologia preventiva.

quantidade que cubra toda a escova. Em contrapartida, o mesmo resultado não foi encontrado no estudo realizado por Sanchez et al. ${ }^{12}$ (2012) onde apenas 33\% dos cuidadores indicaram a quantidade correta de dentifrício.

Constatou-se, a respeito do flúor, que a maioria dos educadores responderam corretamente sobre a sua importante função na prevenção e controle da cárie. Os educadores conheciam de maneira simplificada e abrangente, porém deveriam saber como o flúor de fato age para prevenir a cárie, explicando aos seus alunos o que acontece com seus dentes, após um bochecho com flúor, por exemplo ${ }^{8,11}$. Deve ser enfatizada também a necessidade do uso de creme dental com flúor pelas crianças na concentração convencioal (1000 a 1500ppm), de maneira a desmistificar a sociedade sobre o fato de criança não poder usar creme dental fluoretado.

A escova é um instrumento de autocuidado simples, de baixo custo e de eficácia clínica incontestável para a prevenção da cárie dentária e da doença periodontal ${ }^{14}$. A respeito do tipo de escova dental que deve ser utilizada pelas crianças, foi constatado um elevado nível de acerto, uma vez que um grande número de educadores descreveram que deveria ser pequena e com cerdas macias. A opção pela escova macia foi observada também em estudos prévios ${ }^{6,11}$. É importante ressaltar que, apesar de sua importante contribuição para a higiene bucal, as escovas dentárias podem ser uma fonte de transmissão de vários microrganismos, por isso, a identi-
BISPO JR

VALENTE AGLR

ANDRADE LHR

TANNURE PN

CONHECIMENTO

DOS EDUCADORES

DO ABRIGO

TEREZA DE

JESUS SOBRE

SAÚDE BUCAL

INFANTIL

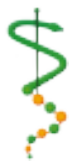

REV, ODONTOL,

UNIV, CID, São

PAULO

2015; $27(3): 202$ -

9 , SET-DEZ 
$B I S P O \quad J R$

VALENTE AGLR

ANDRADE LHR

TANNURE PN

CONHECIMENTO

DOS EDUCADORES

DO ABRIGO

TEREZA DE

JESUS SOBRE

SAUUDE BUCAL

INFANTIL

208 ficação correta das escovas armazenadas nas escolas é importante para evitar que microrganismos patógenos sejam transferidos de uma escova para outra por meio do contato entre elas ${ }^{14}$. Os educadores demonstraram um excelente resultado quanto ao que seria mais importante na escovação dental. Em torno de 92,7\% referiram ser a técnica utilizada mais importante do que a força aplicada e a quantidade de creme dental, semelhante a um estudo previamente publicado ${ }^{6}$.

Como limitação deste estudo, pode-se relatar uma dificuldade em se conseguir entrevistar todos os educadores. O abrigo tem 68 funcionários contratados e apenas 55 participaram da pesquisa. O motivo dessa diferença no número deve-se a licença ou férias de alguns funcionários.

Uma forma efetiva e eficiente no desenvolvimento de atividades educativas em escolas ocorre pelo estabelecimento de parcerias entre profissionais de saúde e professores ${ }^{2}$, através de programas educativos e preventivos na área, possibilitando formar crianças com perfil em educação odontológica, capazes de realizar sua própria promoção de saúde bucal.

\section{CONCLUSÃO}

Os educadores pesquisados apresentaram um razoável conhecimento sobre a etiologia da cárie e doença periodontal, entretanto, relataram um satisfatório conhecimento sobre odontologia preventiva. Os fatores idade do educador e tempo de trabalho não mostraram associação com o grau de conhecimento sobre saúde bucal. Há, portanto, a necessidade da introdução de um projeto visando transferir informações sobre saúde bucal à população estudada e estreitar a ligação entre os educadores e cirurgiões-dentistas.

\section{REFERÊNCIAS}

1. Santos PA, Rodrigues JA, Garcia PPNS. Avaliação do conhecimento dos professores do ensino fundamental de escolas particulares sobre saúde bucal. Rev Odontol UNESP 2002 31(2):20514.

2. Ferreira JMS, Massoni ACLT, Forte FDS, Sampaio FC. Conhecimento de alunos concluintes de Pedagogia sobre saúde bucal. Interface (Botucatu) 2005 ago;9(17):381-8.

3. Vasconcelos R, Matta ML, Pordeus IA, Paiva SM. Escola: um espaço importante de informação em saúde bucal para a população infantil. PGR-Pós-Grad Rev Fac Odontol São José dos Campos 2001 set/dez;4(3):43-8.

4. Mouradian WE. The face of a child: children's oral health and dental education. J Dent Educ 2001 Sep;65(9):821-31.

5. American Academy of Pediatric Dentistry. Definition of dental neglect. Pediatr Dent 1995-1996 1(1):17-26.
6. Aragão AKR, Sousa PGB, Ferreira JMS, Duarte RC, Menezes VA. Conhecimento de professores das creches municipais de João Pessoa sobre saúde bucal infantil. Pesqui bras odontopediatria clín integr 2010 10(3):set.-dez.

7. Antunes LS, Antunes LAA, Soraggi MBS, Corvino MPF. Conhecimento dos profissionais da educação infantil sobre saúde bucal: um estudo quali-quantitativo. Arq odontol 2007 43(2):42-7.

8. Garcia PPNS, Santos PA, Castro CF, Oliveira ALBM, Dotta EAV. Conhecimento de cárie dental e doença periodontal de professores do ensino fundamental segundo o tipo de instituição (pública ou privada). Odonto 2010 jul/ dez; 18(36):155-63.

9. Wyne AH, Al-Ghorabi BM, Al-Asiri YA, Khan NB. Caries prevalence in Saudi primary schoolchildren of Riyadh and their teachers' oral health knowledge, attitude and practices. Saudi Med J 2002 Jan;23(1):77-81. 
10. Simon-Soro A, Mira A. Solving the etiology of dental caries. Trends $\mathrm{Mi}$ crobiol 2015 Feb;23(2):76-82.

11. Garbin CAS, Rovida TAS, Peruchini LFD, Martins RJ. Conhecimento sobre saúde bucal e práticas desenvolvidas por professores do ensino fundamental e médio. RFO, Passo Fundo 2013 set/ dez;18(3):321-7.

12. Sanchez C, Sabatine A, Teixeira $P$, Santos W, Moi G. Perfil do conhecimento dos cuidadores de uma creche pública sobre os hábitos de higiene bucal, Várzea Grande/MT. Conectionline 2012 7(1):2-12.
13. Barreto DM, Paiva SM, Ramos-Jorge ML, Ferreira MC. Avaliação da eficácia de uma atividade educativopreventiva com pré-escolares: estudo piloto de um ensaio clínico randomizado. Arq Odontol, Belo Horizonte 2013 jul/ set;49(3):113-21.

14. Garbin CAS, Rovida TAS, Garbin AJÍ, Arcieri RM, Souza NP, Moimaz SAS. Saúde bucal e educação infantil: avaliação do desgaste e do acondicionamento de escovas dentárias utilizadas por pré-escolares. Rev odontol UNESP (Online) 2012 mar-abr;41(2):81-7.

Recebido em 12/01/2016

Aceito em 08/03/2016
$B I S P O \quad J R$

VALENTE AGLR

ANDRADE LHR

TANNURE PN

CONHECIMENTO

DOS EDUCADORES

DO ABRIGO

TEREZA DE

JESUS SOBRE

SAÚDE BUCAL

INFANTIL 